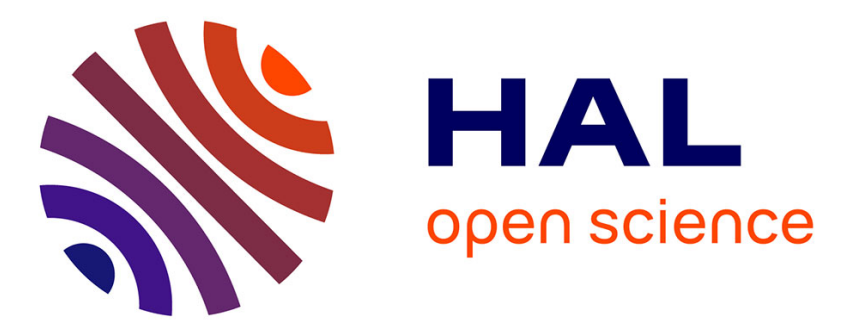

\title{
Processing of DC SQUIDs for radiofrequency amplification
}

R. Chicault, M. Cyrille, Y. Berthier, J. Villégier, F. Pourtier, H. Moriceau, S. Nicoletti

\section{- To cite this version:}

R. Chicault, M. Cyrille, Y. Berthier, J. Villégier, F. Pourtier, et al.. Processing of DC SQUIDs for radiofrequency amplification. Journal de Physique IV Proceedings, 1994, 04 (C6), pp.C6-261-C6-266. 10.1051/jp4:1994642 . jpa-00253138

\section{HAL Id: jpa-00253138 https://hal.science/jpa-00253138}

Submitted on 1 Jan 1994

HAL is a multi-disciplinary open access archive for the deposit and dissemination of scientific research documents, whether they are published or not. The documents may come from teaching and research institutions in France or abroad, or from public or private research centers.
L'archive ouverte pluridisciplinaire HAL, est destinée au dépôt et à la diffusion de documents scientifiques de niveau recherche, publiés ou non, émanant des établissements d'enseignement et de recherche français ou étrangers, des laboratoires publics ou privés. 


\title{
Processing of DC SQUIDs for radiofrequency amplification
}

\author{
R. Chicault, M.C. Cyrille, Y. Berthier, J.C. Villégier*, F. Pourtier*, H. Moriceau* and S. Nicoletti** \\ Laboratoire de Spectrométrie Physique, BP. 87, 38402 Saint Martin d'Hères cedex, France \\ * LETI, DOPT-Commissariat à l'énergie atomique, 17 rue des Martyrs, 38054 Grenoble cedex 9, France \\ ** CNR-Lamel, Via Gobetti, 101-40129 Bologna, Italy
}

\begin{abstract}
The goal of this studies is to use dc Squids as low noise radiofrequency amplifier $(\mathrm{Tn} \approx 1 \mathrm{~K}$ ) in the frequency range $1-150 \mathrm{Mhz}$ and to integrate them in NMR probe. DC Squids have been built using planar technology and with two types of superconducting materials: low $\mathrm{Tc}(\mathrm{Nb})$ and $\mathrm{High} \mathrm{Tc}\left(\mathrm{YBa}_{2} \mathrm{Cu}_{3} \mathrm{O}_{7}\right)$.

Contrary to the traditional set up used in magnetometry (flux locked loop) the dc Squid is here fluxed biased near $\phi z=(2 n+1) \phi_{o} / 4$ and no flux locked loop is connected. Small variations of flux $\left(\phi_{S}<<\phi_{0}\right)$ introduced from signal source via the input coil are amplified following the transfer characteristic $V_{\phi}=\mathrm{dV} / \mathrm{d} \phi$.

The low Tc devices are set up to now the best, concerning the reproducibility and the qualities of the Josephson Junctions obtained with a three layer process $\mathrm{Nb} / \mathrm{Al}_{-} \mathrm{Al}_{2} \mathrm{O}_{3} / \mathrm{Nb}$. Such junctions have been realized following the so called SNOP process, without anodization. The main characteristic obtained at $4.2 \mathrm{~K}$ are $\mathrm{RJ}_{\mathrm{J}} / \mathrm{R}_{\mathrm{N}}=10,2 \Delta=2.8 \mathrm{mev}$ and a Josephson current density $\mathrm{J} \approx 10^{3} \mathrm{~A} / \mathrm{cm}^{2}$.

The high Tc devices have been built with bi-epitaxial $\mathrm{YBa}_{2} \mathrm{Cu}_{3} \mathrm{O}_{7}$ junctions and with a $30 \times 30 \mu \mathrm{m}^{2}$ area loop. $\mathrm{I}(\mathrm{V})$ and $\mathrm{V}(\phi)$ characteristics curves obtained are promizing for applications as RF detection in the temperature range: $4-77 \mathrm{~K}$.

Modelization studies are currently in progress for the optimization of those devices (low Tc and high Tc) as RF amplifiers (minimization of parasitic capacitance between the input coil and the Squid loop) in order to increase their upper frequency limit.
\end{abstract}

* This work is partially supported by Ultimatech (CNRS), by the "région Rhône-Alpes" and E.E.C. "HTSC-GBJ" programs n07100.

\section{INTRODUCTION:}

The goal of this studies is to use DC SQUIDs as low noise RF amplifiers in the $1-150 \mathrm{MHz}$ frequency range in order to integrate them in NMR probe. Such experience have been proved by C. Hilbert and J. Clarke(1).

For such preamplifier use, the DC SQUID is flux biased near $\phi_{z}=(2 n+1) \phi_{O} / 4$ in order to obtain a maximum $\mathrm{dV} / \mathrm{d} \phi$ where $\phi$ is the flux in the SQUID loop created by the input signal in the transformer. However DC SQUID can also be used in a double stage configuration allowing an higher gain and an output impedance in the range 50 to $100 \mathrm{ohms}$ (see fig1), as demonstrated by R.P. Welty and J.M. Martinis (2). In the single stage SQUID amplifier, the bandwith is limited by the parasitic capacitance between the coupling transformer and the SQUID loop . 


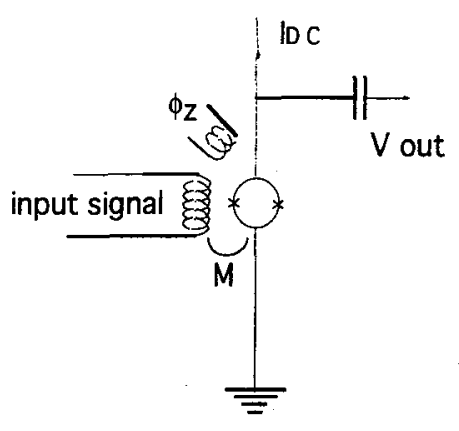

a) Single stage amplifier

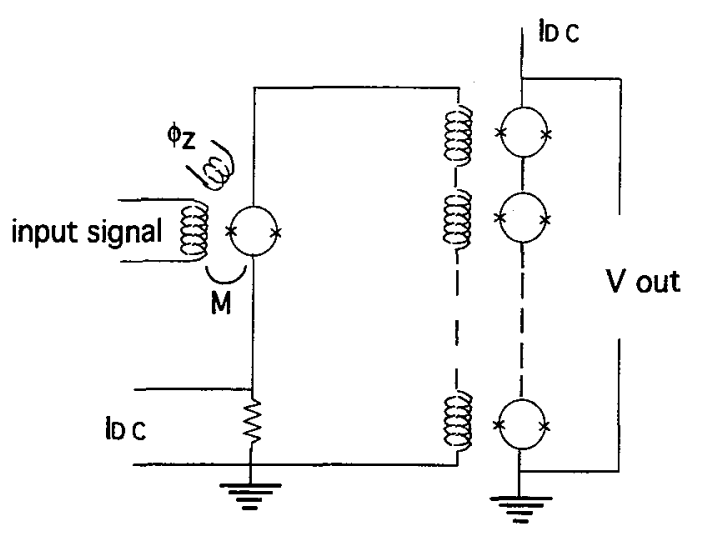

b) Double stage amplifier

figure 1

Takami et al (3) have shown the improvement obtained in the gain and noise temperature by using of a tuned input circuit. On the other hand, the use of a 2-stage configuration increases the SQUID gain and the dynamic range.but limits the bandwith to about a few hundred of $\mathrm{kHz}$.

Up to now, low $T_{c}$ DC SQUIDs have been extensively used due to their good performance concerning noise temperature. However new high $T_{c}$ material DC SQUIDs have been fabricated in order to work close to $77 \mathrm{~K}$, but only preliminary results are available (4) concerning their use as low noise amplifiers. We first present the main parameters of the SQUID we study in view of low noise radio frequency amplification and we describe the different steps of the fabrication process.

\section{FABRICATION OF NIOBIUM JOSEPHSON JUNCTIONS AND SQUIDS USING THE "SNOP" PROCESS (Selective Niobium Overlap process)(5)}

Junctions definition involves some critical steps:

A $300 \mathrm{~nm}$ thick $\mathrm{Nb} / \mathrm{Al}-\mathrm{Al}_{2} \mathrm{O}_{3} / \mathrm{Nb}$ trilayer is deposited on a 3 inches silicon substrate. The depositions are performed using dc-magnetron sputtering and the oxide barrier is made on a $10 \mathrm{~nm}$ of aluminium film oxidized in a pure oxygen ambient pressure.

The trilayer is etched by R.I.E. using SF6 through a photoresist stencil patterned by optical lithography. The profile of which presents overhangs suitable for lift-off (5).

A $300 \mathrm{~nm}$ thick $\mathrm{SiO}_{2}$ layer is deposited by thermal evaporation followed by lift-off. $\mathrm{SiO}_{2}$ walls remain around a weak line of trilayer preventing contacts between the line and the subsequent metallized deposited layer.

A contact $\mathrm{Nb}$ layer is then deposited and etched to interconnect the junctions.

Such junctions have been built with an area in the range 30 to $2 \mu \mathrm{m}^{2}$. The typical characteristics obtained at $4.2 \mathrm{~K}$ are $\mathrm{RJ}_{\mathrm{J}} / \mathrm{R}_{\mathrm{N}}=10,2 \Delta=2.8 \mathrm{meV}$ and a Josephson current density $\approx 10^{3} \mathrm{~A} / \mathrm{cm}^{2}$.

\subsection{Low TC DC SQUIDs fabrication process:}

In order to build a SQUID, two Josephson junctions must be integrated in a system including the SQUID loop, the input transformer, insulating levels, contact lines and pads. Each layer must be patterned by a photoresit stencil followed by a subsequent etch. The main problem of the last step is to avoid the etching of the under layers. To solve it, an optical control by in situ laser reflectrometry can be used.

the following:

The low TC SOUID fabrication process schematically showed on figure 2 can be described as a molybdenum layer is deposited and etched to pattern the junction shunt resistors. Contact pads are defined by depositing and chemicaly etching a thin gold layer. A Nb layer is deposited and etched to define the SQUID loop followed by an insulating layer deposition $\left(\mathrm{SiO}_{2}\right)(1)$. The $\mathrm{Nb} / \mathrm{Al}^{-} \mathrm{Al}_{2} \mathrm{O}_{3} / \mathrm{Nb}$ trilayer is deposited and etched. $\mathrm{A} \mathrm{SiO}_{2}$ (2) layer is then deposited and removed by lift-off in order to 
isolate the trilayer sidewalls. The contacting $\mathrm{Nb}$ layer is deposited after a short backsputter cleaning of the top of the trilayer. The junctions are patterned by etching the contacting layer and the input transformer is defined as connects between the junctions, the resistors, and the contact pads.

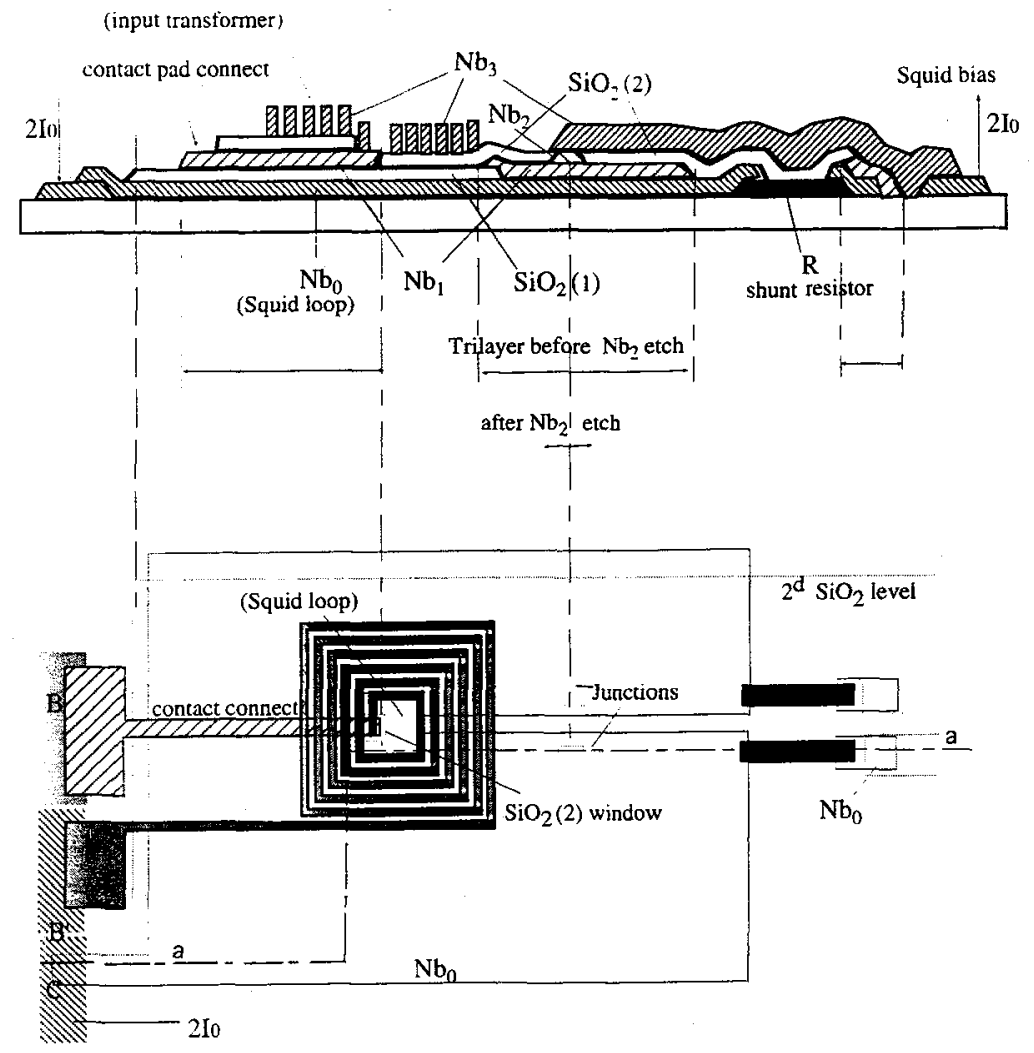

figure 2: Shematic cross-section and partial top views of the dc-squid

\subsection{Typical parameters of DC SOUIDs:}

The typical Squid parameters have been calculated taking into account the constraints of high frequency application. They are summarized in the following table.

\begin{tabular}{|ll|}
\hline loop inductance & $\mathrm{L}=200 \mathrm{pH}$ \\
bias current & $\mathrm{Io}=16 \mu \mathrm{A}$ \\
Junctions surface & $\mathrm{S}=8 \mu \mathrm{m}^{2}$ \\
Josephson current density & $\mathrm{J} / \mathrm{S}=100 \mathrm{~A} / \mathrm{cm}^{2}$ \\
Mac Cumber parameter & $\mathrm{Bc}<1$ \\
input loop inductance & $\mathrm{Li}=50 \mathrm{nH}$ \\
mutual inductance & $\mathrm{Mi}=2 \mathrm{nH}$ \\
coupling coefficient & $\mathrm{k}=0.6$ \\
shunt resistor & $\mathrm{R} \approx 5 \mathrm{ohms}$ \\
\hline
\end{tabular}




\section{FABRICATION OF BI-EPITAXIAL YBCO JOSEPHSON JUNCTIONS AND SQUIDS}

Among 4 types of YBaCuO Josephson junctions (and SQUIDs ) presently studied at LETI : "Edge junctions", "Trilayer junctions", "Bi-crystal junctions", and "Bi-epitaxial junctions" this contribution will be focused on the last one.

\section{1 Control of the epitaxial deposition with $\mathrm{MgO}$ nucleation laver inducing a $45^{\circ}$ in-plane rotation of the cristallographic axes of $\mathrm{CeO}$;:}

The bi-epitaxial process has been firstly developped by Char et al ${ }^{(7)}$ for making $45^{\circ}$ angle Grain Boundary YBCO Junctions ("GBJ") and DC-SQUIDs.

\section{Deposition of $Y B a C u O / C e O$ bilayer $/ \mathrm{MgO}$ process on $S r T i O_{3}$ substrates:}

The best results have been obtained when the $\sim 10 \mathrm{~nm}$ thick $\mathrm{MgO}$ seed layer covered by a $\sim 15 \mathrm{~nm} \mathrm{CeO}_{2}$ layer are deposited by laser ablation, from $\mathrm{Mg}$ and sintered $\mathrm{CeO}_{2}$ targets at respectively $600^{\circ} \mathrm{C}$ and $780^{\circ} \mathrm{C}$ under oxygen pressures ( see figure 3 ).

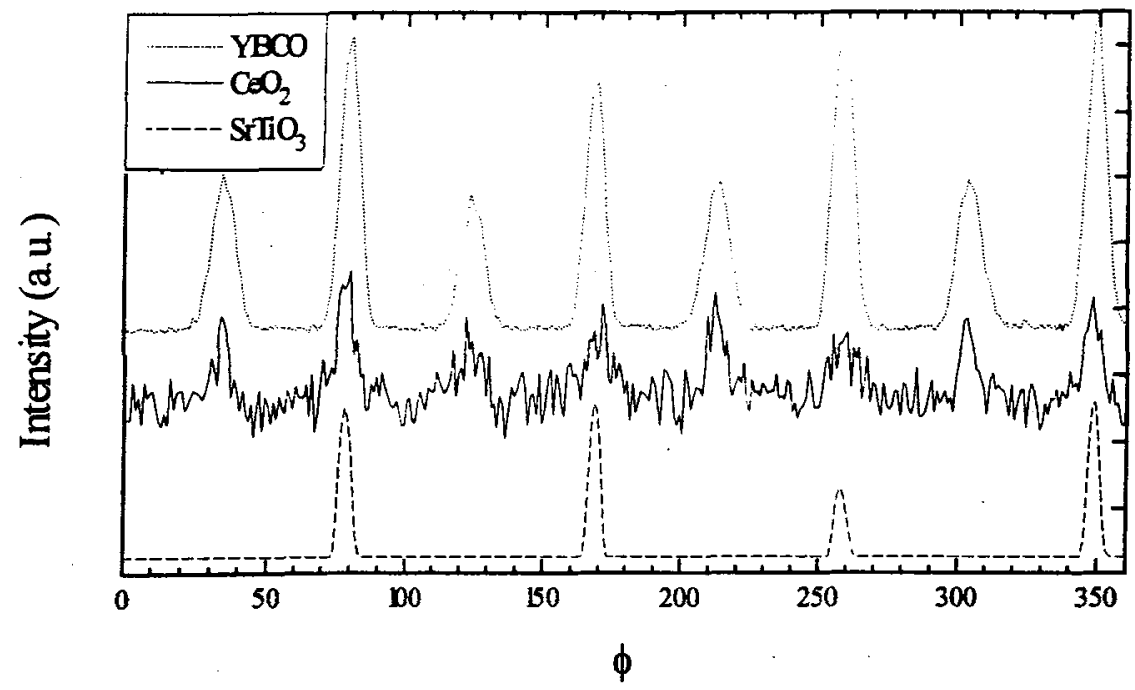

figure 3: $\varphi$-scan diffraction patterns of [204] $\mathrm{SrTiO}_{3},[204] \mathrm{CeO}_{2}$ and [108] $\mathrm{YBaCuO}$ reflections. The $45^{\circ}$ tilted in-plane cristalline orientation on both sides of the artificial grain boundary is evidenced by the 8 diffraction peaks for each $\mathrm{CeO}_{2}$ and $\mathrm{YBaCuO}$ films.

After the first patterning and etching of areas in this bilayer in order to induce the artificial boundaries, a second $(\sim 15 \mathrm{~nm}) \mathrm{CeO}_{2}$ and $(150-250 \mathrm{~nm}) \mathrm{YBaCuO}$ films are deposited at $780^{\circ} \mathrm{C}$ and $750^{\circ} \mathrm{C}$ respectively, either by laser ablation or by $\mathrm{ICM}$ sputtering. This latter $\mathrm{CeO}_{2}$ thin film is used as a buffer layer in the patterned area. From this layer, the $45^{\circ}$ in-plane rotation is induced on both sides of the artificial boundary. The bi-epitaxy have been evidenced using X-Rays diffraction patterns: $(\theta-2 \theta)$ scans, $\varphi$-scans and pole figures.

The process is also presently developped on $\mathrm{MgO}$ and sapphire substrates using $\mathrm{MgO}$ thin films as seed layers, $\mathrm{CeO}_{2}$ and $\mathrm{SrTiO}_{3}$ films as buffer layers; theses substrates with low dielectric constant and low losses are required for the high frequency applications. In the case of sapphire substrates, $\mathrm{CeO}_{2}$ thin films have appeared to be a good buffer layer as previouly reported ${ }^{(8)}$. $\mathrm{GdBaCuO}$ films, deposited on such buffer layers, have a high Tco point (Tc $>89 \mathrm{~K}$ ). 


\section{2 Patterning of the junction arrav:}

5 to $20 \mu \mathrm{m}$ wide junctions have been patterned using optical lithography and argon ion milling. Single junction, serial junction and Squid have been so defined. Au contact pads are sputtered through a mechanical mask. Au wires are bonded onto the contact pads, using thermo-compression apparatus.

\section{3 Junction tests:}

Typical electrical tests have been performed such as (I-V) at various temperatures and under microwave irradiation.The (I-V) follow the "RSJ" model up to $77 \mathrm{~K}$. Critical currents in the $10^{2}-10^{3} \mathrm{~A} / \mathrm{cm}^{2}$ range have been measured at low temperature and of few tens of $\mathrm{A} / \mathrm{cm}^{2}$ close to $77 \mathrm{~K}$. It could have been

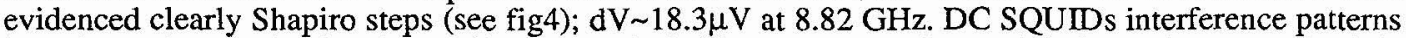
have been characterized under applied magnetic fields up to $77 \mathrm{~K}$. The modulation voltage amplitude is of the order of $10 \mu \mathrm{V}$ at $60 \mathrm{~K}$ as shown on figure 5 .
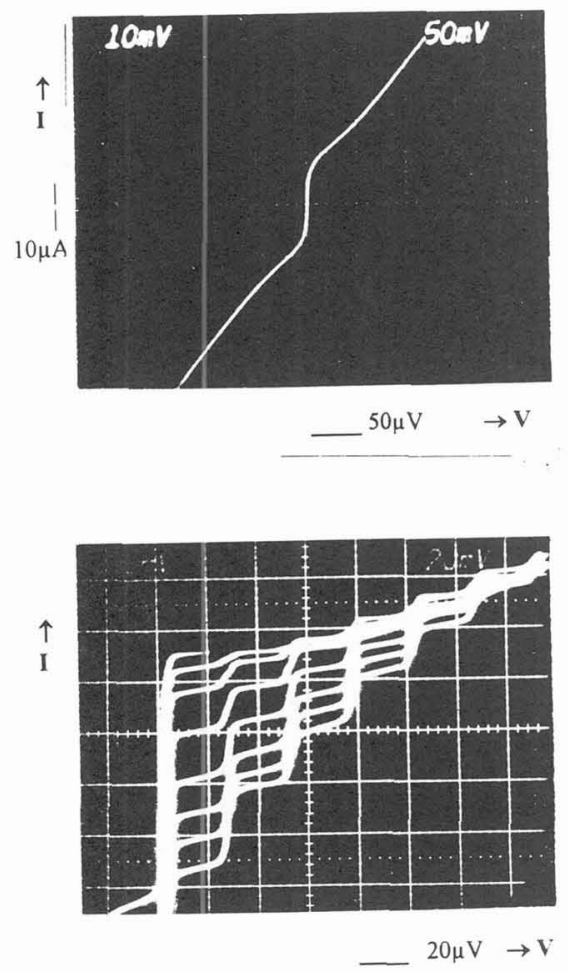

figure 4

a) (I(V) curve for a $10 \mu \mathrm{m} \times .2 \mu \mathrm{m}$ GB Josephson junction at 70K. RSJ type.

b) Shapiro steps measured at $10 \mathrm{~K}$ under microwave irradiation(12.19 Ghz)
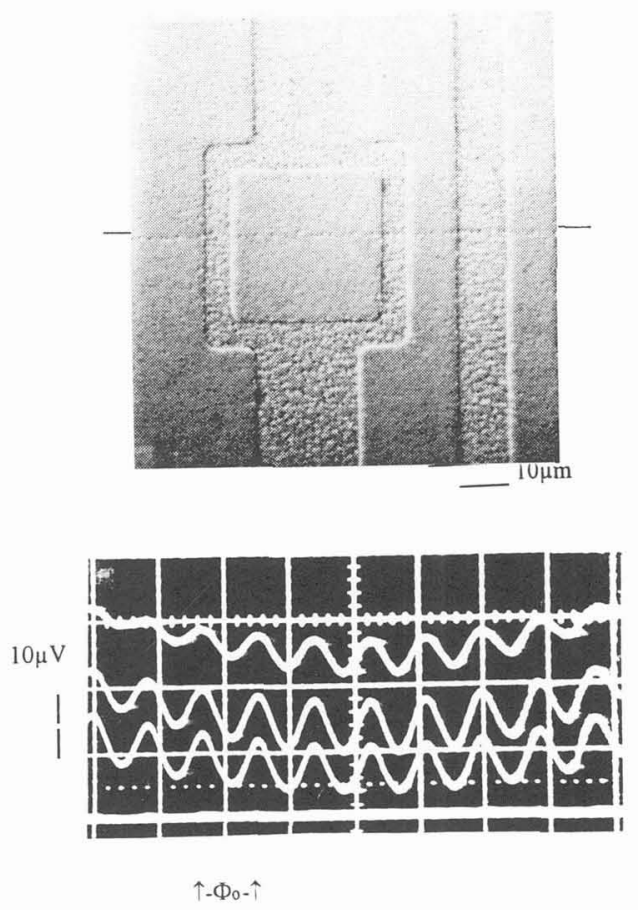

figure 5

a) DC Squid and single GB junction: grain boundary is enhanced with the dark line.

b) Voltage modulation under magnetic field at $55 \mathrm{~K},\left(30 \times 30 \mu \mathrm{m}^{2}\right.$ hole DC Squid $)$ 


\section{REFERENCES:}

[1] C. Hilbert and J. Clarke, J. of Low Temp. Phys.61,263(1985).

[2] R.P. Welty and J.M. Martinis, IEEE Appl Superconductivity, vol.3 , n¹(1993).

[3] T. Takami, T. Noguchi and K. Hamanaka, IEEE Trans Mag 25 n², p.1030 (1989).

[4] Ilmenau and Siemens contribution to E.E.C. SUPACT internal report.

[5] J.C. Villégier, L. Vieux Rochas, M. Goniche, P. Renard and M. Vabre, IEEE Trans Mag.21, 498(1985).

[6] M.Hatzakis, B.J.Canavello, J.M. Shaw, IBM. J.Res. Develop, vol24, nº4 (1980).

[7] K. Char, M.S. Colclough, S.M. Garrison, N. Newman and G. Zaharchuk; "Bi-epitaxial grain-boundary junctions in YBCO", Appl. Phys. Lett. 59, 733 (1991).

[8] F. Wang, M. Siegel, R. Smithey, J. Geerk, G. Linker and O. Meyer; "High Tc Superconductor Thin Films"; L. Correra Editor; Elsevier Sciences Publisher, p. 611(1992). 